DOI: https://doi.org/10.47405/mjssh.v6i10.1125

\begin{tabular}{|c|c|}
\hline 4 & Malaysian Journal of Social Sciences and Humanities (MJSSH) \\
\hline $\begin{array}{l}\text { Malaysian Juoural of } \\
\text { Social ccciecces and }\end{array}$ & Volume 6, Issue 10, October 2021 \\
\hline (MJ-sSH) & e-ISSN : 2504-8562 \\
\hline & $\begin{array}{l}\text { Journal home page: } \\
\text { www.msocialsciences.com }\end{array}$ \\
\hline
\end{tabular}

\title{
Social Media Influencers and The Dietary Choices Among University Students
}

\author{
Syahruddin Ahmad', Diandra Eleanor Bruno ${ }^{1}$ \\ 1 Universiti Malaysia Sabah (UMS), Malaysia \\ Correspondence: Syahruddin Ahmad (syahag@ums.edu.my)
}

\begin{abstract}
This study investigated the attitude and subjective norms of students on Social Media Influencers (SMIs) towards the behavioural intent on their dietary choices in accordance with the Theory of Reasoned Action. Social media influencers as groups of people have had to some extent constructed a reputation for themselves through applying social media platforms to promote oneself. In completing the study, the final year students in Universiti Malaysia Sabah (UMS) were selected as the respondents. The results of the study showed there is a significant relationship between the subjective norms of students on SMIs with the behavioral intent on their dietary choices. Thus, the study concluded that attitude of students towards the SMIs does not affected their daily dietary choices, however, the subjective norms in the students' life on the SMIs actually makes a difference in their eating habits. Based on the findings of the study, $97.6 \%$ of the students believed that they have healthy dietary choices. This study also shows that, $98.8 \%$ of the respondents subscribe to social media influencers on their social media accounts. The findings alone indicated that the students' live are impacted by them. Furthermore, most of them follow the social media influencers on every social media platform: Instagram, Facebook, YouTube, TikTok and Twitter. However, Instagram is the most used social media platform to subscribe to them.
\end{abstract}

Keywords: Social Media Influencers (SMIs), dietary choices, behavioral intent, university students, attitude

\section{Introduction}

These days, there is no doubt that young adults, especially university students have their own social media accounts and on their own account, they are following at least one influencer on any social media sites (Khalid et al., 2018). Each user on the platform has their own interest and there are variety of social media influencers (SMIs) on the internet. Social media influencers are groups of people that have constructed a reputation for themselves through applying social media platforms to promote oneself (Lokithasan et al., 2019). There are beauty influencers, fashion influencers, food influencers, fitness influencers and etc. All of these SMIs somehow managed to always inspire their users in doing something new i.e., influencing their opinion on their lifestyle (Khalid et al., 2018). These influencers initiate trends over the social networks, and they play a significant role in shaping the opinions of users on the internet (Qualman, 2012). As an influencer, their opinions played an important role in the lifestyles of young adults as they are viewed as the dominant users (Nandagiri \& Philip, 2018) on the social networking such as Instagram, Twitter, Facebook, YouTube. This is due to their opinion influences the thoughts of users - mostly young adults. 
Nowadays, the SMIs also influences the attitude and behaviour of young adults over their dietary choices (Khalid et al., 2018). When it comes to dietary choices, it is significant to practice a wellbalanced diet as bad diets such as consuming junk food, skipping meals, as well as a lack of adequate diet are known to trigger different health issues. A well dietary choices it is an essential part of life since it may influence long-term health consequences (Ansar et al., 2015).

Correspondingly, a healthy diet is also considered to have an important part in the lives of university students. This is due to students' physical well- being and cognitive stability can be strengthened by maintaining a healthy diet. Per the international research findings (Stock \& Larsen, 2008; Peltzer et al., 2014) student life in the university environment is characterised by many changes in eating behaviours and nutritional patterns. According to multiple researches (Deliens et al., 2014; Alves \& Boog, 2007), students frequently resorted in bad eating habits and had low dietary health throughout their transition from high to university. At this time, proper nutrition is essential for ensuring overall health, and achieving excellent educational success.

\section{Background of Study}

Today's society is not the same as the one ten years earlier. People adapt into the way the world is today and so does the society around them. Their choices of lifestyles are heavily influenced by so many factors which includes their level of education, interpersonal influences, social networks and etc. As the world and the people are continuously evolving, maintaining a healthy lifestyle could be the most difficult thing to do. At the present time, the dietary choices of young adults are believed to be affected by a variety of rationale. Other than genetics, lifestyles are actually the culprit behind the poor dietary choices among people nowadays. Poor dietary choices can result in obesity which can ultimately lead to multiple health concerns such as diabetes, cardiovascular diseases and many more serious health concerns.

Based on the National Health and Morbidity Survey (NHMS) 2019, discovered that 30.4 percent of adults in Malaysia were overweight and 19.7 percent obese. Beyond any doubt the reason behind those result was poor diet. The Malaysian Dietary Guidelines advice people to limit the intake of foods high in fats and to eat plenty of fruits and vegetables every day. However, based on the NHMS data alone, it was proven that there is a numberof Malaysians who do not comply to such dietary guidelines.

The prevalence of poor diet and eating behaviors among university students in Malaysia is growing. This can be supported by the study performed by Radzi et al. (2019), where the outcome of the study stated that the number of university students in Malaysia who are obese actually goes beyond the national average and this is actually worrying. Given the students' busy schedule and them having to live away from their family, contributes to the reason they are not eating well. Normally, people who practice healthy eating behaviour in the course of studying in the university are more inclined to practice that particular behaviour later on in their life. On the contrary, those students who did not practice healthy eating in the university are more inclined to continue doing so even after they graduated (Sanusi, 2020).

Even with the existence of the Malaysian Dietary Guidelines, no doubt that young adults do not pay much attention to such guidelines as the study conducted by Sugathan and Bagh (2014), stated that the obesity rates among university students in Malaysia range from 14 percent to 32 percent which is considered relatively high. Therefore, since students are technically the future of Malaysia, it is significant to discover the basis behind the university students poor dietary choices.

Since the world nowadays actually revolve around social media, young adults especially students are the ones who spend the most time being on social media. As reported by the Digital Information World (2019), people aged between 16-24 years old spend the most time on social media. On the grounds of this, there must be a connection between social media and the students' dietary choices as technically they spend half of the day being on social media. 
Serman and Sims (2020) also believe that the influencers have the power to influence others by their lifestyle, buying habits, their attitude and their behavior. As the number of blog content posted by the influencers increases, it leads to changes to people's buying habits. Thus, they have the skills of documenting their lives in such a way to the point that they are able to inspire people instantly, which makes them interesting. As claimed by Hermanda et al.(2019), social media users implicitly regarded social media influencers as role models for their lifestyle because the users were able to see correlations between them and influencers in the social media. In other words, the SMIs have the ability to connect with their users on such a level to the point that they are willing to let them affect their process in decision-making.

Social media influencers technically are the owner of the internet (McCorquodale, 2019) as they regulate the direction, the type of content people watch, the products people buy, and the thoughts people have to an extent. To put it another way, the influencers seem to have a powerful influence on the lifestyle of their devoted followers. Therefore, there must be a reason that people tend to trust the opinion of the influencers to the extent that they are often dominated by the opinion of the influencers. By way of illustration, most young adults with social media accounts are following at least one SMI of their own liking and they will prefer to listen to the advice of the influencers for the reason that these influencers always seem remarkably reliable in the world of social media. The SMIs are also known as the modern opinion leaders as their opinion tend to have the biggest impact on young adults. Take for example, a social media influencer posted on his blog about his opinion on the recent coffee shop in which he describes it to be peaceful and a great place to do his work while having coffee, the moment he postedit, his followers will be influenced by his opinion.

Nowadays, the internet and social media serves as a well-known place where people search for health information (Mete et al., 2019). The social media has become a place where anyone can share information regarding nutrition without being a certified dietician or nutritionist (Granheim et al., 2020). As an influencer, their opinions played an important role in the lifestyles of young adults as they are viewed as the dominant users on the social networking sites such as Instagram, Twitter, Facebook, TikTok and YouTube. Therefore, without question, the students are actually allowing the social media influencers to guide them in any areas of their lives. As in view of the fact that more people are becoming dependent on social media influencers, they are actually resorting to social media whenever they have any inquiries on any areas of their lives as this is more convenient for them. All they had to do is take out their phone and search for it over the internet. Therefore, again, this alone indicated a relation between the influencer and the lifestyle of students regarding their dietary choices.

\section{Problem Statement}

Young adulthood is a life stage in peoples' lives where they started to developlife skills that will affect their life in the long run and these days, the existence along with the rise of social media influencers (SMIs) affected every area of peoples' lives specifically on their food choices. Data revealed that the formation of habits and likings are related to media use (Basil, 1990) along with the choices of food (Birch, 1999). It is pivotal to shape the right eating habits during young adulthood as high chances is, the habits they formed now, whether it is good or bad, will remain in their live throughout adulthood.

Young adults are consistently fascinated by the fame of the SMIs, and they are their main source of information including fashion tips, food choices and etc. Thus, they tend to build online relationship with the influencers andunder those circumstance, the SMIs are able to shape their followers lifestyle.As the number of social media influencers increases, there is an issue on thembeing unreliable. As claimed by Lofft (2020), some of the influencers are actually unqualified nutritionist and yet, when they post health-related content on their social media accounts, people tend to believe them. Some influencers claimed to be a 'nutritionist' over the internet by selling personalised diets when they are not even a certified nutritionist, and this raises an issue that it is significant to acknowledge that not all social media influencers are what they claimed to be over the internet. 
Since the social media influencers have the ability to talk about diets and health information with such credibility over the internet, people are more prone into believing them even though, the information that they posted on the internet might not be true. Hence, there must be a reason behind people listening to the opinion of the social media influencers even though there are news informing people that the influencers are most often not what they claimed tobe.

The internet has formed a digital food environment which the communication about food and nutrition is prevalent through multiple social media sites. "Digital activities on social media have transformed how health information is communicated and how the public engages with it" (Fernandezet al., 2020). That being the case, the rise of the internet has truly emerged in so many ways to the point that it exerts influence upon how people communicate about food nowadays.

A study made in 2019 had revealed that children and teenagers that have their own social media apps, are exposed to unhealthy food and drinks that came from content posted from the SMIs or from advertisements. The result of the study found out that teenagers viewed more food related content on social media than children and most of them were exposed with unhealthy food products like fast food. The study focused solely on children and teenagers aging between 7-16 years old in Canada (Kent et al., 2019). Most often the SMIs posted content on social media of them eating variety of junk food, this is a way for them to promote the chosen food brand. Due to the creativity of the influencers in promoting the food, for sure they would be drawn into purchasing the food even though it might not be healthy for them.

On that account, a study is required to investigate the relationship between social media influencers and the attitudes and the behaviour of young adults. So far, there is less study conducted on that matter. Thus, researcher will find out whether social media influencers have positive relationship towards the attitude and behavior of students towards their dietary choices. Researcher will focus solely on the final year students in Universiti Malaysia Sabah as they are young adults with social media accounts, and they are the ones who spend the most time on social media.

\section{Research Objective}

i. To investigate whether there is a significant relationship between the attitude on social media influencers with students' behavioral intent on theirdietary choices

ii. To investigate whether there is a significant relationship between the subjective norm on social media influencers with students' behavioral intenton their dietary choices

iii. To investigate the role of social media influencers and students' dietary choices

\section{Research Question}

The research questions for this study are:

i. Does attitude on social media influencers have significant relationship with students' behavioral intent on their dietary choices?

ii. Does subjective norms on social media influencers have significant relationship with students' behavioral intent on their dietary choices?

iii. What is the role of social media influencers and students' dietary choices?

\section{Literature Review}

Beyond doubt, individuals around the world today use social media applications to communicate and exchange information as mass communication channels like the television, newspapers and radio are no longer serving as the dominant place to search for information. Nowadays, people are more dependent on the online personae - social media influencers (SMIs), for information like lifestyle, food, 
technology, beauty and so on (Yuan \& Lou, 2020). According to research, the social media influencers are known as celebrities and role models among people (Gleason et al., 2017).

The social media influencers would often build their online personae on social media platform such as Instagram, YouTube, Facebook and etc. An article mentioned that the SMIs are now 'taking over the world' (Roose, 2019) as their online personality alone have the ability to capture the attention of people around the world and they have the power to influence the behaviour of their followers as well. Studies showed that the influencers have the power to influence the way people perceive brands, products and most companies nowadays are relying on the influencers as a way for them to promote their brands (Almousa et al., 2020; Voramontri \& Klieb, 2019). With this, certainly the influencers are also able to influence students regarding their attitude on their dietary choices.

In this study, the influencers power towards the dietary choices of students will be investigated as current research pertaining to how the influencers affected the attitude and behaviours of university students towards their dietary choices in Sabah is still very limited. Thus, this chapter discusses relevant literature denoting to dietary choices and social media influencers. This chapter also discuss the theory that is used in this study as guidance to conduct this research. Furthermore, the theory will be further explained along with conceptual framework to help further understand the theory used in this research.

\section{Dietary choices in the use of social media}

Preedy and Watson (2010) stated that dietary choices are the daily choices developed by individuals or group on the choices of food they consumed. They suggested that the reasonable dietary choices actually involve a variation of vitamins, minerals, proteins, carbohydrates and fats where these variations take part in the wellbeing of humans. Presently, the usage of social media affected the eating attitudes and behaviours of people (Papathomas et al., 2019) as numbers of research has been done to investigate the relationship between social media and nutrition where they had actually found relation between those two variables. Social media has the potential to improve the dietary choices for young adults. However, only a few studies evaluated the effectiveness of social media components.

A study by Holland and Tiggeman (2016) found constant positive relationships between the usage of social media, disordered eating and body dissatisfaction, the result showed social media has a negative effect on body image and the eating behaviour of people. The term 'insta-norm' was created to reflect the power of social media towards the practices of nutrition happening on Instagram and the norm around Instagram is the concept of 'ethno-nutritionism', where Atkinson (2011) explained the concept as extreme dietary practices. Based on the research by Holland and Tiggeman (2016), social media platforms portrayed the popular diet-related 'insta-norms' which affected youth to practice such extreme diets which eventually affected their health. Their study suggested that interventions must be conducted as social media influenced unhealthy eating behaviours towards youth and that it is important to increase the social media literacy among young adults.

Research showed the dietary choices of university students are generally bad as students showed more tendency to consume less vegetables and fruits and reported high intake of high-calorie foods (Deshpande et al., 2009). This research can be supported by Sogari et al., (2018) where they found university students are more inclined to gain weight due to poor eating habits and thus, they believed that it is significant to increase the knowledge regarding healthy dietary choices among university students.

Swindle et al. (2018) study found that Facebook is a practical platform to educate on nutrition to engage parents in a preschool obesity prevention. Hence, they used Facebook to deliver health-related education to educate parents in improving nutrition for young children. They also discovered that the more teachers post content regarding nutrition, the more parents understood the concept of healthy eating. However, currently there are still limited study targeting the university students regarding which social media platform is suitable for them to learn about nutrition values. 
Klassen et al. (2018) argued social media serves as potential tool to support healthier food choices among young adults. The result showed that using social media to facilitate healthier dietary choices among young adults requires careful and thorough experimental designs as social media could contribute to poor dietary choices in young adults. Thus, Klassen et al. (2018) suggested more research is needed to investigate social media use in supporting healthier dietary choices among young adults. Accordingly, based on Sidani et al. (2016), the influence of social media towards eating concerns do not receive much attention, they discovered there is a strong coalition between social media use and eating behaviour among young adults in America. However, they suggested a more specific research on the influence of social media characteristics is required to investigate further on the impact of social media towards the eating behaviour of young adults.

According to Lofft (2020), the number of Canadians relying on social media as their source of health information is increasing. Based on the 2019 survey conducted by Statistics Canada, it was revealed that nearly six in 10 Canadians aging under 35 depended on social media when it comes to finding information regarding their health. This can be supported by Pollard et al. (2016) and Hayes et al. (2016) where researchers also found out that people use the Internet as source of nutrition information. Lofft (2020) also stated that they prefer to look up to the social media influencers blogs or tweets whenever they wanted to search for health informations on the internet. However, only five percent of Canadians reported being well educated about health information. The study only proved that the influencers play a role in shaping the dietary behaviour of Canadians even though the influencers are not authorised doctors.

\section{Social Media Influencers (SMIs)}

Social Media Influencers (SMIs) portray the up-to-date form of the unconventional third-party endorser that have the power to influence peoples' lifestyle through the means of social media such as Twitter, Instagram, Facebook, YouTube and other social media sites (Freberg et al., 2011). Social media influencer is a third-party person with high social standing and acquire the skills of a strong social influence (Lu et al., 2012), or micro-celebrities or social media stars (Gaenssle \& Budzinski, 2020). Social influence includes both deliberate and accidental attempts in convincing people to alter their values, behaviours and actions (Gass, 2015). In simpler terms, social media influencers are those people who gain popularity in social media sites as a result of their creativity that can attract numbers of followers into subscribing to them as for example, the famous Malaysian SMIs - Samantha Lee, a food influencer who created an Instagram page about food. She had over $621 \mathrm{k}$ followers on Instagram and there is no doubt that it was her creativity and online personae that attract that many followers.

Nowadays, most organisation employ the SMIs as a way for them to influence and persuade consumers. As claimed by Zak and Hasprova (2020), the action of consumers decision-making process is heavily influenced by the modern opinion leaders - the social media influencers. Zak and Hasprova (2020) study stated that the opinion leaders affected the attitudes, opinions and thoughts of consumers. Based on the result of the study, they found that the promotions of products by the SMIs are actually more successful than products that are not promoted by the influencers. Thus, influencers have the most impact on clothes, shoes, cosmetics. However, the study also stated that people do not rely on the SMIs regarding their food buying decision-making process.

This can be supported by Gashi (2017), as the study claimed that the influencers are responsible for influencing consumers' purchase decision. In Gashi (2017) study, it was found that the expertise of the SMIs in creating content, their attractiveness, social identity and trust had actually proved that they play a significant role in consumers' purchase decision process. Then again, it was their online personae that ultimately gives them the power to influence their followers as a result of their impact through the content they posted and their ability to form an online relationship with their followers.

According to Freberg et al. (2011) study, the social media influencers' success is to all intents and purposes is important to brands. This is due to, the fame and the power of the SMIs can easily attract people into purchasing the brand they are posting on their social media sites. The result showed that brands are depending on the SMIs to promote their company. With this, the study proved that the 
SMIs have the power on branding. In addition to that, even though the SMIs can easily attract people into purchasing a brand positively (Zak \& Hasprova, 2020), they also have the power to negatively influenced the brand. All of this goes back to the way they promote the product. Thus, the study showed that, not all influencers can bring positive impact to brands.

Furthermore, Lokithasan et al. (2019) said that there are differences between male and female influencers' way of influencing people in their lives. Their study showed that female influencers that promote beauty products tend to attract female followers whilst male are more into male influencers that promote games and technology. Lokithasan et al. (2019) also said that their respondents are attracted to the influencers mainly due to entertainment factor and for further information regarding the products that they represented. Their study also claimed that female respondents prefer influencers who posted more information than entertainment, however, this was not the case from the male respondents.

Lofft (2020) argued that social media influencers impacted the lives of young adults in so many ways as they have a way of shaping the identity of their followers especially now in the age of social media. Besides influencing consumers' purchase decision and branding, influencers also affected the lives of young adults on their eating habits. Studies showed the foundation of habits and food preferences are linked to the consumption of social media use (Lofft, 2020). This can be supported by the study conducted by Almousa, Alsaikhan and Aloud (2020) where the result of their study stated that social media has a crucial role in shaping the dietary behaviors of people in Saudi Arabia. They added the role of influencers should be monitored carefully by the ministry of health especially when it comes to producing content on social media regarding food as it could lead to unhealthy diets. However, there is less study in Malaysia when it comes to the relationship between the role of influencers and dietary behaviors of young adults.

Futhermore, research by Turner and Lefevre (2017) found that body dissatisfaction are linked to the influence of these micro-celebrities (SMIs). The result of their study showed positive relationship between the usage of social media and eating disorders among young adults and in some serious cases, it had actually led to orthorexia nervosa - a compulsion of eating healthily, which eventually led to excessive weight loss and is linked to depression. Hence, this study proved even though SMIs have positive impacton brand image and companies, it might not be the same in some cases. Thus, Turner and Lefevre proved there is a relation between social media influencers and eating disorders among young adults. This can be supported by Wayles (2020) where researcher proved the relationship between Instagram and eating disorders among young adults.

Along with it, based on Alruwaily et al. (2020) study, children influencers created millions of unhealthy dietary choices perceptions by commercial advertising. The research conducted in America found that the young SMIs YouTube channel featuring them eating unhealthy food like McDonald's were collectively viewed more than 48 billion times. Based on the result of the study, through watching the children influencers digesting unhealthy food on YouTube, it actually persuaded the young viewers into adapting to the same unhealthy lifestyles. Hence, again, the study proved that young SMIs have the power on influencing childrens' dietary choices. However, there is still less study in Sabah regarding the social media influencers impact on university students' dietary choices.

The study aims to understand Universiti Malaysia Sabah students' attitudes and norms towards the social media influencers on their dietary choices, the researcher will be attempting to grasp a better understanding from the perspectives of the students, studying specifically on how their intention is affected by the above variables. The theory of reasoned action predicts behavioral intention which actually acts as a middle ground between estimating attitudes and actually predicts behaviour. The theory analyses the problems that limit the influence of attitudes as the behavioural intention actually differ from behaviour. Thus, the theory helps researcher to predict the behaviour of students based on their attitudes and norms towards the SMIs 


\section{Methodology}

In this paper, all variable's measures are developed on existing measurements established from prior scholars. The measures from the Theory of Reasoned Action were validated in this research along with the lists of questions provided by Skylie Galea's research on Social Media Influencers on Purchase Decision in 2020. The measurement constructs involved attitude, subjective norm and behavioural intention. The questionnaire was also adapted and modified with the accordance of Azjen and Fishbein's 1975 Theory of Reasoned Action.

A five-point likert scale were applied on measuring students' attitude and subjective norm on social media influencers on their dietary choices based on the Theory of Reasoned Action. The five-point likert scale ranging from 'strongly agree' to 'strongly disagree' was established in this study. Researchers claimed that the five-point liker scale would decrease the respondents' frustration level of patient while increasing rate of response and quality (Sachdev \& Verma, 2004). The theory is also utilized in investigating the behavioral intention of students as well.

A total of 100 online questionnaires were distributed to the final year students in Universiti Malaysia Sabah. However, only 82 questionnaires were returned. Based on the G*Power sample size analysis for the study, the required sample size for the present study is 74 and researcher received a total of 82 responses. Thus, the present study sample size of 82 is acceptable and appropriate for further data analysis.

The final sample of the study consist of 82 respondents where $28.0 \%$ of them were male and the remaining $72.0 \%$ were female. $81.7 \%$ (67 respondents) of them were in the age range of 21-23 years old while $18.3 \%$ (15 respondents) of them were between 24-26 years old.

The ethnicity of the respondents is randomly selected from different background. $64.6 \%$ (53 respondents) were Bumiputera Sabah, 9.8\% (8 respondents) were Bumiputera Sarawak, 3.7\% (3 respondents) were Chinese, 20.7\% (17 respondents) were Malay and the remaining $1.2 \%$ (1 respondent) were Indian. When it comes to respondents' residency, $68.3 \%$ (56 respondents) of them were non-resident and the remaining $31.7 \%$ (26 respondents) were residential.

\section{Result}

\section{Social Media Influencers and Dietary Choices}

Table 1 indicates the frequency and valid percentage of the items regarding the role of social media influencers and the dietary choices of respondents.

Table 1: Role of SMIs and Dietary Choices of Students

\begin{tabular}{llll}
\hline Items & Categories & Frequency & $\begin{array}{l}\text { Valid } \\
\text { Percentage }\end{array}$ \\
\hline Do you follow any social & Yes & 81 & $98.8 \%$ \\
media influencers? & No & 1 & $1.2 \%$ \\
Which social media platforms do you & Instagram & 74 & $90.2 \%$ \\
follow them on? & Facebook & 46 & $56.1 \%$ \\
& YouTube & 44 & $53.7 \%$ \\
& TikTok & 33 & $40.2 \%$ \\
Do you believe to have & Twitter & 24 & $29.3 \%$ \\
healthy dietary choices? & Yes & 80 & $97.6 \%$ \\
\hline
\end{tabular}

Based on the table, $98.8 \%$ of respondents said yes to following the social media influencers on social media. $90.2 \%$ of the respondents chose Instagram as the social media platform that they follow them 
on, 56.1\% chose Facebook, 53.7\% chose YouTube, 40.2\% TikTok and $29.3 \%$ chose Twitter. Consequently, $97.6 \%$ said yes when asked whether they believe to have healthy dietary choices and the remaining $2.4 \%$ said no.

\section{Correlation Analysis}

Pearson correlation coefficient analysis is computed in SPSS in order to rest the strength and the direction of the relationship among the entire attribute of the study. When the correlation value is $\mathrm{r}=0.10$ to 0.29 or $\mathrm{r}=-0.10$ to -0.29 , it is regarded little or weak; when the value is $\mathrm{r}=0.30$ to 0.49 or $\mathrm{r}=-$ 0.10 to -0.29 , it is considered medium or moderate; and when the value is $r=0.50$ to 1.0 or $r=-0.50$ to 1.0 , it is recognised large or strong. The values of Pearson correlation coefficients range from -1.00 to +1.00. A value of +1.00 signifies a high positive correlation, a value of -1.00 means negative correlation, and a value of 0.00 indicates that there is no linear relationship between two variables (Pallant, 2007).

According to Table 2, the results indicate that the construct of attitude is positively and moderately correlated with behavioural intent due to its correlation coefficient values which is 1.000 . Meanwhile, the construct of subjective norms also showed positively and moderately correlated with behavioural intent with coefficient values of .452

Table 2: Correlation Analysis of study variables

\begin{tabular}{lllll}
\hline Dependent Variable & Independent Variable & Correlation & $\begin{array}{l}\text { Significance (1- } \\
\text { tailed) }\end{array}$ & df \\
\hline Behavioural Intention & $\begin{array}{l}\text { Attitude } \\
\text { Subjective } \\
\text { Norms }\end{array}$ & 1.000 & .249 & 0 \\
& .452 & .000 & 79 \\
\hline
\end{tabular}

\section{The Relationship between Attitude and Behavioral Intent}

The first hypothesis (H1) investigates whether there is a significant relationship between the attitude of students towards social media influencers and their behavioural intent on their dietary choices. It specified that there is no significant relationship between the attitude of students and their behavioural intent on their dietary choices $(\beta=.110, \mathrm{p}<0.05)$. Therefore, hypothesis $(\mathrm{H} 1)$ is rejected.

\section{The Relationship between Subjeєtive Norms and Behavioral Intent}

The second hypothesis $(\mathrm{H} 2)$ investigates whether there is a significant relationship between the subjective norm towards the social media influencers and the students' dietary choices. Thus, for the second hypothesis $(\mathrm{H} 2)$, there is a significant relationship between subjective norms and behavioural intent $(\beta=.721, \mathrm{p}<0.05)$. Therefore, hypothesis $(\mathrm{H} 2)$ is accepted.

The study's results and findings were presented in this chapter. The result of the reliability analysis as well as the descriptive analysis were provided. Moreover, the corelation and regression analysis of the subjective norms on the influencers were significant.

\section{Conclusion}

The intention of this study was to investigate students' attitude and subjective norms on social media influencers among the final year students in Universiti Malaysia Sabah. Furthermore, this study also investigates the relationship between social media influencers and students' behavioural intent on their dietary choices. Therefore, in completion of this study, the three research questions are as follows:

i. Does attitude on social media influencers have significant relationship 
ii. with students' behavioural intent on their dietary choices?

iii. Does subjective norms on social media influencers have significant

iv. relationship with students' behavioural intent on their dietary choices?

v. What is the role of social media influencers and students' dietary

vi. choices?

The discussion looks into the following research issues relating to; (1) the students' attitude on social media influencers with the behavioural intent on their dietary choices, (2) their subjective norms on social media influencers with the behavioural intent on their dietary choices, and (3) the role of social media influencers with the dietary choices of students.

\section{The relationship between students' attitude on social media influencers and their behavioral intent}

According to the literature on attitude, the degree to which a person has a good or bad assessment of a certain conduct is linked to as their attitude (Bada \& Sasse, 2014). The concept of attitude is also referred to as cognitive because according to expert, memories can build up a person's attitude (Eagly \& Chaiken, 1993). The present study focuses on the attitude of students on the social media influencers towards the behavioural intent on their dietary choices. To date, there is still little research conducted on this area.

In the process of correlation analysis, the attributes of attitude were computed in SPSS to determine the relationship between attitude and students' behavioural intent. The findings of this study indicated that the construct of attitude is positively and moderately correlated with behavioural intent. This indicated that there is a relationship between the attitude of students on social media influencers towards their behavioural intent on their dietary choices, however, the relationship indicates only a moderate relationship between the variables.

In the process of regression analysis to analyse the direct relationship between attitude and behavioural intent, the constructs of attitude were also computed through the means of SPSS. With that, findings showed that there is no significant relationship between the attitude of students on social media influencers and their behavioural intent on their dietary choices. Thus, the present study first hypothesis is rejected. According to Wang et al. (2017), the facts that social media influencers disseminate has the potential to impact people's beliefs, behaviours, and attitudes. However, for this present study, findings indicated that social media influencers do not have enough impact on the attitude of the final year Communication students in Universiti Malaysia Sabah regarding their dietary choices.

\section{The relationship between students'subjective norms and their behavioral intent}

Based on literature, subjective norms imply to a feeling of duty to act in a certain manner (Lokhorst, 2009). Subjective norms refer to a person recognizing what another person believe about a particular behaviour, hence, that behaviour of that person is influenced. The present study focuses on the subjective norms of students on the social media influencers where their behavioural intent on their dietary choices is investigated.

In the process of correlation analysis, the findings of the study indicates that the construct of subjective norm is positively and moderately correlated with behavioral intent. This showed subjective norm in this study has a relationship on the social media influencers towards their behavioural intent though result showed only moderate relationship.

Furthermore, in the process of regression analysis through the means of SPPS, the findings showed that there is a significant relationship between subjective norms and behavioural intent. Thus, the second hypothesis of the present study is accepted. Ajzen and Fishbein (1980) believed that another people's 
opinion on a particular subject will dictate how the other person behave. In other words, people are inclined to the social pressure to behavein a certain way.

Based on this study, the final year students are pressured by the social norms to behave in a certain way. In this case, their behavioural intent on their dietary choices is influenced by their subjective norms towards the social media influencers. Bada and Sasse (2014) believed that people engage in a certain behaviour if their peers do the same, and for this study, it is proven that subjective norms play a significant role in shaping students' behavioral intent.

\section{The role of social media influencers and students' dietary choices}

According to the literature on social media influencers, Lu et al. (2012) mentioned them as someone who acquire the skills of a strong social influence where people who possess such skills can convince people to alter their values, behaviours and actions (Gass, 2015). Prior research showed that the social media influencers influenced the lives of young adults to the point they can shape their identity as well (Loff, 2020). In this study, the role of social media influencers toward students in Universiti Malaysia Sabah is investigated. Based on the findings of the study, $98.8 \%$ of the respondents subscribe to social media influencers on their social media accounts. This finding alone indicated that the students' live are impacted by them. Furthermore, most of them follow the social media influencers on every social media platform: Instagram, Facebook, YouTube, TikTok and Twitter. However, Instagram is the most used social media platform to subscribe to them.

Based on existing literature, the daily choices of an individual on the type of food they consumed are called dietary choices (Preedy and Watson, 2010). Prior research found out that they found constant positive relationship between the use of social media and disordered eating (Holland \& Tiggeman, 2016). The dietary choices of students are generally bad as they are more inclined to consume less vegetables and fruits (Deshpande et al., 2009). Sogari et al. (2018) found that university students mostly have poor eating habits. In this study, the dietary choices of students are investigated. However, based on the findings of the study, $97.6 \%$ of the students believed that they have healthy dietary choices.

\section{References}

Albarracin, D., \& Shavitt, S. (2018). Attitudes and Attitude Change. Annual Review of Psychology, 69(1), 299-327. doi:10.1146/annurev-psych-122216-011911

Almousa, M., Alsaikhan, A., \& Aloud, A. (2020). The Influence of Social Media on Nutritional Behavior and Purchase. International Journal of Marketing, Communication and New Media, 8, 78-94

Allen, M. (2017). Correlation, Pearson. The SAGE Encyclopedia of Communication Research Methods. doi:10.4135/9781483381411.n99

Babbie, E., \& Mouton, J. (2007). Practice of Social Research. Oxford UniversityPress Southern Africa.

Baccarella, C. V., Wagner, T. F., Kietzmann, J. H., \& McCarthy, I. P. (2018). Social media? It's serious! Understanding the dark side of social media. European Management Journal, 431-438. Retrieved from www.elsevier.com/locate/emj

Bada, M., Sasse, A., \& Nurse, J. R. (2015). Cyber Security Awareness Campaigns: Why do they fail to change behaviour? Retrieved from Global Cyber Security Capacity Centre: https://www.researchgate.net/publication/274663655_Cyber_Security_Awar eness_Campaigns_Why_do_they_fail_to_change_behaviour

Basil, M. D. (1990). Primary News Source Changes: Question Wording, Availability, and Cohort $\begin{array}{llll}\text { Effects. } & \text { Uournalism }\end{array}$ doi:https://doi.org/10.1177/107769909006700425

Bell, E., \& Bryman, A. (2007). The Ethics of Management Research: An Exploratory Content Analysis. British Journal of Management, 63-77. doi:10.1111/j.1467-8551.2006.00487.x 
Berthon, P., Pitt, L., Kietzmann, J., \& McCarthy, I. P. (2015). CGIP: Managing Consumer-Generated Intellectual Property. Sage Journal, 57(4), 43-62.doi:https://doi.org/10.1525/cmr.2015.57.4.4

Birch, L. L. (1999). Development of food preferences. Annual Review of Nutrition, 19, 41-62. doi:10.1146/annurev.nutr.19.1.41

Chau, M. M., Burgermaster, M., \& Mamykina, L. (2018). The use of social media in nutrition interventions for adolescents and young adults-a systematic review. International Journal of Medical Informatics. doi:10.1016/j.ijmedinf.2018.10.001

Deshpande, S., Basil, M. D., \& Basil, D. Z. (2009). Factors Influencing Healthy Eating Habits Among College Students: An Application of the Health Belief Model. Health Marketing Quarterly, 26(2), 145-164. doi:10.1080/07359680802619834

Dudovskiy, J. (2018). The Ultimate Guide to Writing a Dissertation in Business Studies: A Step-by-Step Assistance. Pearson Education Limited.

Eagly, A. H., \& Chaiken, S. (1993). The psychology of attitudes. Pyschology and Marketing, 12(5), $459-466$ Retrieved

from https://www.researchgate.net/publication/258879638 A review Eagly A H_Chaiken_S_1993_ The_psychology_of_attitudes_New_York_Harcourt_Brace_Janovich

Fleming, J., \& Zegwaard, K. E. (2018). Methodologies, methods and ethical considerations for conducting research in work-integrated learning. International Journal of Work-Integrated Learning, 19(3), 205-213. Retrieved from https://files.eric.ed.gov/fulltext/EJ1196755.pdf

Freberg, K., Graham, K., McGaughey, K., \& Freberg, L. A. (2011). Who are the social media influencers? A study of public perceptions of personality. Public Relations Review, 37(1), 90-92. doi:https://doi.org/10.1016/j.pubrev.2010.11.001

Gaenssle, S., \& Budzinski, O. (2020). Stars in social media: new light through old windows? Journal of Media Business Studies, 18(2), 79-105. doi:doi.org/10.1080/16522354.2020.1738694

Gleason, T. R., Theran, S. A., \& Newberg, E. M. (2017). Parasocial Interactions and Relationships in $\begin{array}{lllll}\text { Early Adolescence. Frontiers in Psychology, } & \text { 8, }\end{array}$ doi:https://doi.org/10.3389/fpsyg.2017.00255

Granheim, S. I., Opheim, E., Terragni, L., Torheim, L. E., \& Thurston, M. (2020). Mapping the digital food environment: a scoping review protocol. BMJ Open,10. doi:10.1136/bmjopen-2019-036241

Hair, J. F., Anderson, R. E., Babin, B. J., \& Black, W. C. (2010). Multivariate data analysis: A global perspective.

Hassan, Z. A., Schattner, P., \& Mazza, D. (2006). Doing A Pilot Study: Why Is It Essential? Malays Fam Physician., 70-73. $\quad$ Retrieved https://www.ncbi.nlm.nih.gov/pmc/articles/PMC4453116/\#R01

Hayes, L., Bhochhibhoya, A., Cheney, M., Larson, D., \& Branscum, P. (2016). An Evaluation of the Effects of Formal Nutrition Education on Online Nutrition Information Retrieval among College Students. Journal of Consumer Health on the Internet, 20(4), 139-155. doi:10.1080/15398285.2016.1198878

Hermanda, A., Sumarwan, U., \& Tinaprilla, N. (2019). The Effect Of Social Media Influencer On Brand Image, Self-Concept, And Purchase Intention. Journal of Consumer Sciences, 4(2), 76-89. doi: $10.29244 / j c s .4 .2 .76-89$

Joshi, P. (2018). Mothers' Beliefs towards Children's Food Behavior: A Phenomenological Study. Nepal Journal of Multidisciplinary Research, 1(1).

Johnson, D. M., \& Shoulders, C. W. (2019). Beyond Magic Words and Symbols: Rethinking Common Practices in Quantitative Research. Journal of Agricultural Education, 60(3), 291-303. doi:10.5032/jae.2019.03291

Johanson, G.A. \& Brooks, G. P. (2009). Initial scale development: sample size for pilot studies. Educational and Psychological Measurement, 70(3), 114 - 124.

Kabir, A., Miah, S., \& Islam, A. (2018). Factors influencing eating behavior and dietary intake among resident students in a public university in Bangladesh: A qualitative study. PLoS ONE, 13(6). doi:10.1371/journal.pone.0198801

Khalid, N. L., Jayasainan, S. Y., \& Hassim, N. (2018). Social media influencers - shaping consumption culture among Malaysian youth. SHS Web of Conferences. doi:10.1051/shsconf/20185302008

Klassen, K. M., Douglass, C. H., Brennan, L., Truby, H., \& Lim, M. S. (2018). Social media use for nutrition outcomes in young adults: a mixed-methods systematic review. Int J Behav Nutr Phys Act, 15(1). doi:10.1186/s12966-018-0696-y 
Koo, H. C., Poh, B. K., Lee, S. T., Chong, K. H., Bragt, M. C., \& Talib, R. A. (2016). Are Malaysian Children Achieving Dietary Guideline Recommendations? Asia Pacific Journal of Public Health, 28(5). doi:10.1177/1010539516641504

Lavrakas, P. J. (2008). Convenience Sampling. Encyclopedia of Survey Research Methods. Loeper, A., Steiner, J., \& Stewart, C. (2014). Influential Opinion Leaders. The Economic Journal, 124(581). doi: https://doi.org/10.1111/ecoj.12100

Lim, X. J., Radzol, A. R., Cheah, J.-H., \& Wong, M. W. (2017). The Impact of Social Media Influencers on Purchase Intention and the Mediation Effect of Customer Attitude. Asian Journal of Business Research, 7(2). doi:10.14707/ajbr.170035

Lisichkova, N., \& Othman, Z. (2017). The Impact of Influencers on Online Purchase Intent. Retrieved from Research Gate: https://www.researchgate.net/publication/338107402_The_Impact_of_Influ encers_on_Online_Purchase_Intent

Lofft, Z. (2020). When Social Media Meet Influencer: How influencers spread misinformation and why we believe them. 11. doi:doi:https://doi.org/10.29173/hsi319

Lokithasan, K., Simon, S., Jasmin, N. Z., \& Othman, N. A. (2019). Male And Female Social Media Influencers: The Impact Of Gender On Emerging Adults. International Journal of Modern Trends in SocialSciences, 2(9), 21-30. doi:10.35631/IJMTSS.29003

Lokhorst, A. (2009). Using commitment to improve environmental quality. Retrieved from Leiden University: https://scholarlypublications.universiteitleiden.nl/handle/1887/13998

Lu, D., Li, Q., \& Liao, S. S. (2012). A graph-based action network framework to identify prestigious members through member's prestige evolution. doi:https://doi.org/10.1016/j.dss.2011.12.003

Majid, U. (2018). Research Fundamentals: Study Design, Population, and Sample Size. Undergraduate Research in Natural and Clinical Sciences and Technology (URNCST) Journal. doi:10.26685/urncst.16

McCorquodale, S. (2019). How social media are shaping our digital future. Great Britain: Bloomsbury Publishing Plc. Retrieved from https://books.google.com.my/books?hl=en\&lr=\&id=Ey2qDwAAQBAJ\&oi=fn $\mathrm{d} \& \mathrm{pg}=\mathrm{PP} 1 \& \mathrm{dq}=$ social + media+influencers $\&$ ots=J7tH5RY1 $\mathrm{xr} \&$ sig=PNOZIRY1 JwOTuFQVHX147yHmmHQ\&redir_esc $=\mathrm{y} \# \mathrm{v}=$ onepage \&q\&f=false

McMillan, J. H., \& Schumacher, S. (2010). Research in education: Evidence-based inquiry. Virginia : Upper Saddle River, NJ: Pearson Education.

Mete, R., Shield, A., Murray, K., Bacon, R., \& Kellett, J. (2019). What is healthy eating? A qualitative exploration. Public Health Nutrition, 22(13), 2408- 2418.

Memon, M. A., Ting, H., Ramayah, T., Chuah, F., Cheah, J-H. (2017). A Review of the Methodological Misconceptions and Guidelines Related to the Application of Structural Equation Modeling: A Malaysian Scenario. Journal of Applied Structural Equation Modeling, l(1), i-xiii.

Mills, A. J., Durepos, G., \& Wiebe, E. (2010). Reasearch Framework. Encyclopedia of Case Study Research. doi:https://dx.doi.org/10.4135/9781412957397.n299

Nandagiri, V., \& Philip, L. (2018). The impact of influencers from Instagram and YouTube on their followers. International Journal of Multidisciplinary Research and Modern Education, 61-65. Retrieved from https://www.researchgate.net/publication/323996049 The impact of influe ncers_from_Instagram_and_YouTube_on_their_followers

Nour, M., Yeung, S. H., Partridge, S., \& Allman-Farinelli, M. (2017). A Narrative Review of Social Media and Game-Based Nutrition Interventions Targeted at Young Adults. Academy of Nutrition and Dietetics. doi:10.1016/j.jand.2016.12.014

Paniagua, J., Korzynsk, P., \& Mas-Tur, A. (2017). Crossing borders with social media: Online social networks and FDI. European Management Journal, 314-326. doi:https://doi.org/10.1016/j.emj.2016.09.002

Pannucci, C. J., \& Wilkins, E. G. (2010). Identifying and Avoiding Bias in Research. Plast Reconstr Surg, 126(2), 619-625. doi:10.1097/PRS.0b013e3181de24bc

Papathomas, A., White, H. J., \& Plateau, C. R. (2019). Young people, social media, and disordered eating. UK: Taylor \& Francis Group .

Pollard, C. M., Pulker, C. E., Meng, X., Kerr, D. A., \& Scott, J. A. (2016). Who Uses the Internet as a Source of Nutrition and Dietary Information? An Australian Population Perspective. Journal of Medical Internet Research, 17(8). doi:10.2196/jmir.4548 
Preedy, V. R., \& Watson, R. R. (2010). Handbook of Disease Burdens and Quality of Life Measures. New York: Springer, New York, NY. doi:https://doi.org/10.1007/978-0-387-78665-0_5487

Qualman, E. (2012). Socialnomics: How Social Media Transforms the Way We Liveand Do Business, 2nd Edition.

Radzi, C. W., Jenatabadi, H. S., Alanzi, A. R., M. I., Mamat, M. Z., \& Abdullah, N. A. (2019). Analysis of Obesity among Malaysian University: A Combination Study with the Application of Bayesian Structural Equation Modelling and Pearson Correlation. International Journal of Environmental Research and Public Health, 16(3), 492. doi:10.3390/ijerph16030492

Roose, K. (2019, July 16). "Don't Scoff at Influencers. They're Taking Over the World,". Retrieved from New York Times: https://www.nytimes.com/2019/07/16/technology/vidconsocial-mediainfluencers.html

Sanusi, G. A. (2020). Factors Influencing the Factors to use Malaysian Dietary Guidelines Among University Students. International Journal of Economics, Management and Accounting, 28(2), 517-543. Retrieved from https://journals.iium.edu.my/enmjournal/index.php/enmj/article/view/798

Sachdev, S. B., \& Verma, H. (2004). Relative Importance Of Service Quality Dimensions: A Multisectoral Study. Retrieved fromhttps://www.semanticscholar.org/paper/RELATIVEIMPORTANCE-OF- SERVICE-QUALITY-DIMENSIONS\%3A-SachdevVerma/b9a62fdb45ef1288cde2525a903076d9c42090c9

Sekhon, T., Bickart, B., Trudel, R., \& Fournier, S. (2016). Being a likeable braggart: How consumers use brand mentions for self-presentation on social media. Consumer Psychology in a Social Media World, 23-39. Retrieved from https://psycnet.apa.org/record/2016-02008-002

Serman, Z., \& Sims, J. (2020). How Social Media Influencers Affect Consumers Purchase Habits? UK Academy for Information Systems Conference Proceedings 2020, 10. Retrieved from https://aisel.aisnet.org/ukais2020/10

Sugathan, S., \& Bagh, D. S. (n.d.). Prevalence and Correlates of Overweight and Obesity among Medical Students in Ipoh, Malaysia. Academic Medical Journal of India, 2(1). Retrieved from https://www.researchgate.net/publication/260795338_Volume_II_-

Issue_1_Prevalence_and_Correlates_of_Overweight_and_Obesity_among_M edical_Students_in_Ipoh_Malaysia

Sidani, J. E., Shensa, A., Hoffman, B., Hanmer, J., \& Primack, B. A. (2016). The Association between Social Media Use and Eating Concerns among US Young Adults. Journal of the Academy of Nutrition and Dietatics, 116(9),1465-1472. doi:10.1016/j.jand.2016.03.021

Singh, K. D., \& Onahring, B. D. (2019). Entrepreneurial intention, job satisfaction and organisation commitment - construct of a research model through literature review. Journal of Global Entrepreneurship Research, 9(1). doi:10.1186/s40497-018-0134-2

Sogari, G., Velez-Argumedo, C., Gómez, M. I., \& Mora, C. (2018). College Students and Eating Habits: A Study Using An Ecological Model for Healthy Behavior. Nutrients, 10(12). doi:10.3390/nu10121823

Swindle, T. M., Ward, W. L., \& Whiteside-Mansell, L. (2018). Facebook: The Use of Social Media to Engage Parents in a Preschool Obesity Prevention Curriculum. J Nutr Educ Behav., 50(1), 4-10. doi:10.1016/j.jneb.2017.05.344

Talaue, G. M., AlSaad, A., AlRushaidan, N., AlHugail, A., \& AlFahhad, S. (2018). THE IMPACT OF SOCIAL MEDIA ON ACADEMIC. International Journal of Advanced Information Technology (IJAIT), 8(4). doi:10.5121/ijait.2018.8503

Taber, K. S. (2018). The Use of Cronbach's Alpha When Developing and Reporting Research Instruments in Science Education. Research Sci Edu, 48, 1273- 1296. doi:10.1007/s11165-0169602-2

Turner, P. G., \& Lefevre, C. E. (2017). Instagram use is linked to increased symptoms of orthorexia. Eat Weight Disord, 277-284. doi:10.1007/s40519-017-0364-2

Voramontri, D., \& Klieb, L. (2019). Impact of social media on consumer behaviour. Int. J. Information and Decision Sciences, 11(3), 210-232.doi:doi.org/10.1504/IJIDS.2019.101994

Wagner, T. F., Baccarella, C. V., \& Voigt, K.-I. (2017). Framing social media communication: Investigating the effects of brand post appeals on user interaction. European Management Journal, 1-11. doi:http://dx.doi.org/10.1016/j.emj.2017.05.002 
Wayles, K. (2020). Instagram and Eating Disorders: An Empirical Study of the Effects of Instagram on Disordered Eating Habits Among Young Girls. Theses and Dissertations. Retrieved from https://scholarworks.uark.edu/etd/3595

Xiang, Y. W. (2020, July 27). Malaysia Ranks 2nd In Asia For Cyberbullying Among Youth. Retrieved from Says News: https://says.com/my/news/malaysia- ranks-2nd-in-asia-for-cyberbullyingamong-children

Yuan, S., \& Lou, C. (2020). How Social Media Influencers Foster Relationships with Followers: The Roles of Source Credibility and Fairness in Parasocial Relationship and Product Interest. Journal Of Interactive Advertising, 20(2), 133-147. doi:doi.org/10.1080/15252019.2020.1769514

Zak, S., \& Hasprova, M. (2020). The role of influencers in the consumer decision-making process. Globalization and its Socio-Economic Consequences. 